\title{
Heart Failure Disease Management Program and the Six Months Readmission Rate
}

\author{
Souzan Tatari ${ }^{1 *}$, Abdul Rahman Mourad ${ }^{1}$, Nabil Shasha $^{1}$, Atika Adhami $^{1}$, Raed Osman ${ }^{1}$, Ali El-Sayed ${ }^{1}$, Lama \\ Soubra ${ }^{2}$, Hani Tamim ${ }^{3}$ and Samer Kabbani ${ }^{1}$
}

${ }^{1}$ Rafik Hariri University Hospital, Lebanon

${ }^{2}$ Beirut Arab University, Lebanon

${ }^{3}$ American University of Beirut Medical Center, Lebanon

Submission: April 21, 2017; Published: May 05, 2017

*Corresponding author: Souzan Tatari, Rafik Hariri University Hospital, Lebanon, Tel: +9613833847; Fax: +9611843834; Email: tatary_suzan@hotmail.com.

\begin{abstract}
Aim: To assess the effect of heart failure (HF) disease management program (DMP) on the 6 months readmission rates for patients with chronic HF.

Methods and results: This was a prospective observational clinical trial that was conducted at Rafik Hariri University Hospital during the years 2012-2013. Patients presenting with acute $\mathrm{HF}$ with $\mathrm{EF} \leq 40 \%$ were recruited. We enrolled 151 patients of whom 71 were in the DMP and 80 in the control group. The DMP consisted of 2 phases. Phase I started during the index hospitalization where education about HF, diet and exercise was delivered. Phase II consisted of close follow-up after discharge: at 7 days, 1 month and every 3 months for a total of 6 months. During phase II we enforced low salt diet, daily exercise and augmentation of HF medications. The primary outcome was all-cause readmission rate at 6 months. The secondary outcome was all-cause mortality at 6 months. Patients enrolled in the DMP had a shorter length of stay $(9.5 \pm 7.1 \mathrm{DMP}$ vs. $12.7 \pm 10.5$ control) (P-0.03). All cause readmission rate at 6 months was significantly lower in the DMP (28.2\% DMP vs. 57.5\% control) (P<0.001). All-cause mortality at 6 months tends to be lower in the DMP vs. control (9.9\% vs. 20.0\%, respectively) (P-0.08).
\end{abstract}

Conclusion: A HF-DMP designed with close follow-up after discharge with low salt diet, daily exercise and early augmentation of HF medications will decrease readmission rates at 6 months and tends to reduce mortality when compared to regular care.

Keywords: Disease management program; Heart failure; Readmission rates

\section{Introduction}

Heart failure (HF) is a major cause of morbidity and mortality worldwide and has a significant negative impact on quality of life, health-care costs, and longevity [1-3]. Approximately six million Americans and fifteen million Europeans are living with HF [4]. HF is one of the most common causes of hospitalization and readmission worldwide. HF hospitalization rate in the United States of America (USA) is 23 per 1000 for men over the age 64 years making HF the leading cause of hospitalization in this age group [5,6]. HF is the primary diagnosis in more than 1 million hospitalizations annually in the USA [7]. The average length of stay is 6.3 days and the 6 months readmission rate is roughly $50 \%$ [8]. HF costs $\$ 39.2$ billion annually in the USA with the average cost for each HF hospitalization is $\$ 12,000$ $[4,9]$. In Europe, more than 1 million hospitalizations have been attributed to acute episodes of HF each year [10]. The median length of stay in Europe for HF is 9 days and the readmission rate is $44 \%$ at 1 year [ $11-13$ ]
HF disease management programs are common in North America, Europe, and Australia [14]. These services provide care to optimize pharmacological regimen and support medication management and effective self-care. Programs have been widely introduced following recommendations from international clinical guidelines. The goals of the HF disease management programs included optimization of drug therapy, intensive patient education, and vigilant follow-up with early recognition of problems, identification and management of patients' comorbidities [15-17]. HF patients who were cared for in these programs were shown to have significantly fewer re-hospitalizations, lower healthcare costs, improved functional and symptom status, and better quality of life as compared either with their pre-intervention status or with HF patients being treated with conventional care. However, a number of recent and comparatively large trials have found no or small benefits from these programs [18]. 
Numerous research groups have designed programs that have varied types of interventions from a simple telephone call from a nurse to intensive follow-up by a multidisciplinary team. In general, programs based on periodic contacts have performed better than programs without interventions. Programs combining clinical and educational attention have performed better than those affording only education. Programs carried to the patient's home have performed better than those requiring attendance at a clinic [19]. The objective of our study was to evaluate the effect of a disease management program (DMP) designed by early follow-up by a specialized HF team with early augmentation of HF medications accompanied by education on low salt diet, daily exercise, and self-care on all cause readmission rates at 6 months in patients with HF and reduced ejection fraction when compared to traditional care.

\section{Methods}

The study was a prospective observational clinical trial that enrolled patients presenting with acute HF decompensation during the years of 2012 and 2013 at Rafik Hariri University Hospital (RHUH). RHUH is the largest public hospital in Lebanon with academic affiliation with two medical schools. RHUH is a referral center for patients from all regions in Lebanon. The study was conducted after gaining approval of the Institutional Review Board at RHUH. All patients presenting with acute HF decompensation with $\mathrm{EF} \leq 40 \%$, who were $\geq 18$ years of age, known or recently diagnosed with $\mathrm{HF}$, were willing to participate in such a trial and signed the informed consent were recruited. Patients were excluded if they were $<18$ years of age, refused to sign the informed consent or with dyspnea and fluid overload caused by disease other than HF.

Patients were enrolled in the DMP if they agreed to participate and to complete a 6 months follow-up period. Patients were enrolled as a control group if they agreed to participate in the trial but refused to be in the DMP and elected to receive only regular care by their cardiologist. Patients in the DMP were followed up by a HF team. The team consisted of cardiologist with an expertise in HF, cardiology fellow and a HF nurse. The DMP consisted of two phases. Phase I and phase II.

Phase I started during the index admission till discharge. The patients were educated about HF symptoms, medications, diet restrictions, self-care and the importance of weight and daily exercise. In addition patients were educated about medication compliance and physician's follow-up. During this phase demographic, clinical, laboratory, imaging data and diagnosis at admission were collected. Another set of data was collected at discharge and included discharge status, length of stay and cost for hospitalization. On discharge patients were given a weighing scale and a booklet consisted of teaching instructions and a section for weight and exercise that was required to be filled on daily basis by patients.

Phase II consisted of outpatient follow-up visits with multiple interventions. The first visit was at 7 days after discharge, then at 1 month and every 3 months for a total of six months. During this phase patients were educated to restrict fluids to 1.5 liters per day and salt to less than 2 grams per day. Patients were encouraged to walk for 30 minutes per day for at least 5 days per week. We did our best at each visit to augment their medical regimen in order to reach the target doses of HF medications as recommended by guidelines. A general assessment of the patient clinical status was conducted with identification of new symptoms and signs of early decompensation. Diary checking was conducted at every follow-up visit to ensure adherence to treatment regimen.

The primary outcome of the study was the all cause readmission rate at 6 months. The secondary outcome was all cause mortality at 6 months.

\section{Statistical Analysis}

Data was collected from the two groups and the two phases using case report forms. Data entry was done using the excel sheets for analysis. All statistical analyses were performed using SAS software (version 9.1; SAS Institute, Cary, NC). Continuous variables were presented as mean and standard deviation (SD) and categorical variables as absolute and relative frequencies (\%). Chi-square test and Student t-test were used to compare differences between the groups, as appropriate. Associations were expressed as relative risk and corresponding 95\% confidence intervals (CI). Moreover, stratified analyses were carried out to assess any effect modification of the program by any of the available factors. A multivariate analysis for the predictors of the readmission at 6 months was done as well as the association between all the variables and patient mortality. A P-value $\leq 0.05$ was considered to be statistically significant.

\section{Results}

Table 1: The demographic and clinical characteristics of the patients with HF enrolled in both groups during the index admission.

\begin{tabular}{|c|c|c|c|}
\hline Characteristics & $\begin{array}{c}\text { DMP Group } \\
\text { (N = 71) }\end{array}$ & $\begin{array}{c}\text { Control Group } \\
\text { (N = 80) }\end{array}$ & $\begin{array}{c}\text { P- } \\
\text { Value }\end{array}$ \\
\hline $\begin{array}{c}\text { Age, years } \\
\text { (mean, } \pm \text { sd) }\end{array}$ & $61.2 \pm 11.6$ & $67.9 \pm 11.6$ & 0.001 \\
\hline Gender, \% male & $46(64.8 \%)$ & $48(60.0 \%)$ & 0.55 \\
\hline Known HF, \% & $46(64.8 \%)$ & $51(63.7 \%)$ & 0.89 \\
\hline $\begin{array}{c}\text { Coronary Artery } \\
\text { Disease \% }\end{array}$ & $37(52.1 \%)$ & $47(58.8 \%)$ & 0.41 \\
\hline $\begin{array}{c}\text { Diabetes Mellitus } \\
\%\end{array}$ & $29(40.8 \%)$ & $32(40.0 \%)$ & 0.92 \\
\hline Hypertension \% & $44(62.0 \%)$ & $57(71.3 \%)$ & 0.23 \\
\hline $\begin{array}{c}\text { Atrial Fibrillation } \\
\%\end{array}$ & $27(38.0 \%)$ & $20(25.0 \%)$ & 0.08 \\
\hline $\begin{array}{c}\text { Valvular Heart } \\
\text { Disease \% }\end{array}$ & $18(25.4 \%)$ & $11(13.8 \%)$ & 0.07 \\
\hline
\end{tabular}




\begin{tabular}{|c|c|c|c|}
\hline $\begin{array}{c}\text { Chronic } \\
\text { Kidney Disease } \\
(\mathrm{GFR}<60 \mathrm{ml} / \\
\left.\min / 1.73 \mathrm{~m}^{2}\right) \%\end{array}$ & $8(11.3 \%)$ & $15(18.8 \%)$ & 0.2 \\
\hline NYHA Class I, \% & $2(2.8 \%)$ & $0(0.0 \%)$ & 0.22 \\
\hline NYHA Class II, \% & $9(12.7 \%)$ & $4(5.0 \%)$ & 0.09 \\
\hline NYHA Class III, \% & $18(25.4 \%)$ & $14(17.5 \%)$ & 0.24 \\
\hline NYHA Class IV, \% & $42(59.2 \%)$ & $36(45.0 \%)$ & 0.08 \\
\hline $\begin{array}{c}\text { Systolic Blood } \\
\text { Pressure mmHg } \\
\text { (mean } \pm \text { sd) }\end{array}$ & $134.0 \pm 24.3$ & $126.8 \pm 21.4$ & 0.06 \\
\hline $\begin{array}{l}\text { Heart Rate b.p.m } \\
\qquad(\text { mean } \pm \text { sd })\end{array}$ & $88.8 \pm 21.3$ & $84.3 \pm 15.3$ & 0.14 \\
\hline $\begin{array}{l}\text { Length of stay, days } \\
\qquad \text { (mean } \pm \text { sd) }\end{array}$ & $9.5 \pm 7.1$ & $12.7 \pm 10.5$ & 0.03 \\
\hline $\begin{array}{c}\text { Cost of each } \\
\text { hospitalization }(\$)\end{array}$ & $3320.00 \pm 2785.00$ & $4218.00 \pm 4519.00$ & 0.14 \\
\hline
\end{tabular}

We enrolled 151 patients in this study of whom 71 (47\%) were in the DMP and 80 (53\%) in the control group. At baseline, most of the clinical characteristics were similar between the two groups. However the patients in the DMP were younger (the mean age was $61.2( \pm 11.6)$ vs. $67.9( \pm 11.6), \mathrm{P}-0.001$. The majority were males with $58 \%$ of them had ischemic heart disease as the underlying etiology for HF and 40\% were diabetics. More patients in the DMP group were diagnosed with dyslipidemia (46.5\% vs. $26.3 \%$, P-0.01) and chronic obstructive pulmonary disease (22.5\% vs. $8.8 \%$, P-0.02 respectively). At admission to the hospital there was no significant difference in NYHA classification between the two groups (P-0.45). Majority of patients (89\%) were in NYHA class III and IV. The average EF in both groups was $30 \%$ (Table 1 ).

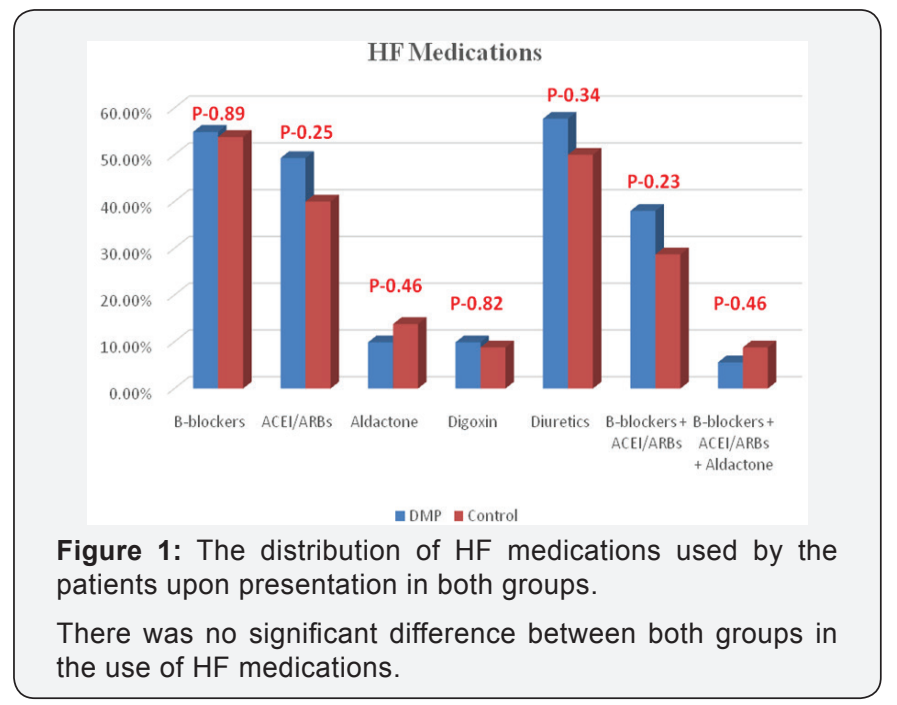

Patients enrolled in the DMP had a significant shorter length of stay in days (9.5 \pm 7.1 DMP vs. $12.7 \pm 10.5$ control group), (P0.03 ).However, the cost of hospitalization was not significantly different (DMP: \$ 3320.00 \pm 2785.00 ) vs. (control: \$ 4218.00 \pm \$ 4519.00), (P-0.14). The readmission rate at 3 months was significantly lower in the DMP (25.4\% in the DMP vs.46.3\% in the control group) (P-0.008) (Figure 1).
The primary outcome of all cause readmissions at 6 months was significantly lower in the DMP (28.2\% DMP vs. $57.5 \%$ control group) $(\mathrm{P}<0.001)$ (Figure 2$)$. The secondary outcome of all-cause mortality tends to be lower at 6 months in the DMP vs. control (9.9\% vs. $20.0 \%$, respectively) (P-0.08) (Figure 3). A multivariate analysis for the predictors of readmissions at 6 months was only significant for the DMP (adjusted OR (95\%CI); 0.26 (0.12-0.56); (P-0.001) (Table 2). When we analyzed the variables that predict mortality, it was shown that the use of digoxin and dobutamine was associated with higher mortality in both groups (P-0.009) whereas the use of $\beta$-blockers was associated with lower mortality (P-0.005) (Table 3). It was shown that the longer the length of stay and the higher rate of readmissions at 3 months were predictors of higher mortality (P-0.04 and P-0.03, respectively).

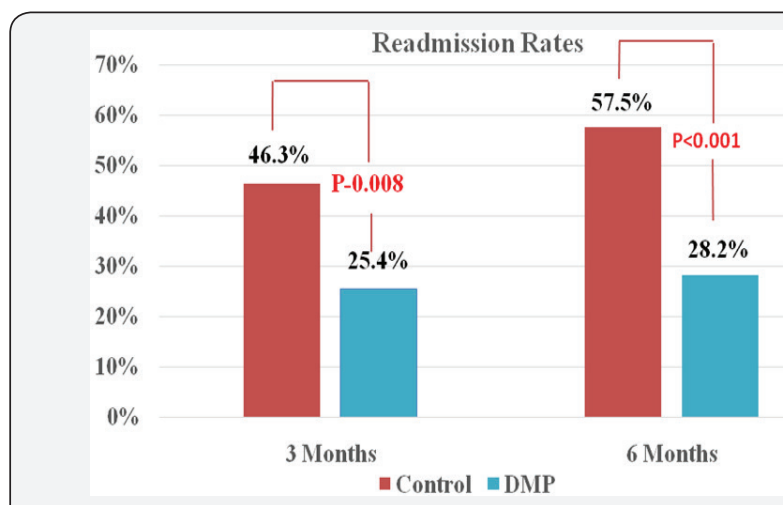

Figure 2: The readmission rate for patients with $\mathrm{HF}$ at 3 and 6 months in both groups.

The primary endpoint of readmission at 6 months was significantly lower in the DMP as compared to the control group.

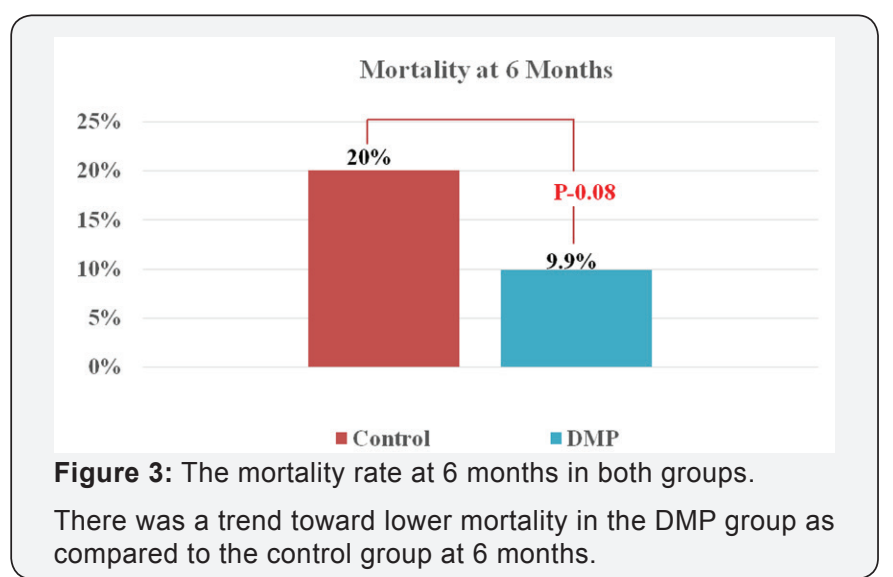

Table 2: Multivariate analysis for the predictors of the readmission at 6 months.

\begin{tabular}{|c|c|c|}
\hline Predictors & $\begin{array}{c}\text { Adjusted } \\
\text { Or(95\%CI) }\end{array}$ & P-value \\
\hline Control/DMP groups & $0.26(0.12-0.56)$ & 0.01 \\
\hline Age & $1.00(0.97-1.03)$ & 0.94 \\
\hline Known heart failure & $1.27(0.52-3.13)$ & 0.6 \\
\hline Coronary artery disease & $0.70(0.30-1.63)$ & 0.41 \\
\hline
\end{tabular}




\section{JOJ Nursing \& Health Care}

\begin{tabular}{|c|c|c|}
\hline Diabetes Mellitus & $1.50(0.71-3.15)$ & 0.29 \\
\hline Chronic kidney disease & $0.82(0.29-2.36)$ & 0.72 \\
\hline Home medication: $\beta$-blockers & $1.23(0.39-3.90)$ & 0.73 \\
\hline Home medication: ACE/ARB & $1.42(0.39-5.13)$ & 0.6 \\
\hline Home medication: Digoxin & $0.52(0.14-1.95)$ & 0.33 \\
\hline Home medication: Diuretics & $1.78(0.63-5.05)$ & 0.28 \\
\hline Home medication: Aldactone & $0.67(0.11-4.05)$ & 0.67 \\
\hline Home medication: $\beta$-blockers & & \\
\hline + ACE/ARB & $0.82(0.17-3.83)$ & 0.8 \\
\hline $\begin{array}{c}\text { Home medication: } \beta \text {-blockers + } \\
\text { ACE/ARB+Aldactone }\end{array}$ & $2.51(0.25-25.17)$ & 0.43 \\
\hline Length of stay & $1.02(0.98-1.06)$ & 0.39 \\
\hline
\end{tabular}

Table 3: The association between medical treatment, length of stay, and readmissions at 3 months with patient mortality.

\begin{tabular}{|c|c|c|c|}
\hline Variables & $\begin{array}{c}\text { Survival } \\
\text { (Number \%) }\end{array}$ & $\begin{array}{c}\text { Mortality } \\
\text { (Number \%) }\end{array}$ & P-value \\
\hline$\beta$-blockers & $118(92.2 \%)$ & $16(69.6 \%)$ & 0.005 \\
\hline ACEI/ARB & $91(71.1 \%)$ & $13(56.5 \%)$ & 0.17 \\
\hline Diuretic & $110(85.9 \%)$ & $19(82.6 \%)$ & 0.75 \\
\hline Aldactone & $36(28.1 \%)$ & $9(39.1 \%)$ & 0.29 \\
\hline Digoxin & $14(10.9 \%)$ & $7(30.4 \%)$ & 0.02 \\
\hline Nitrate & $15(11.7 \%)$ & $4(17.4 \%)$ & 0.49 \\
\hline Ivabradine & $3(2.3 \%)$ & $1(4.3 \%)$ & 0.49 \\
\hline Dobutamine & $8(6.3 \%)$ & $6(26.1 \%)$ & 0.009 \\
\hline Length of stay in days & $10.6( \pm 8.6)$ & $14.8( \pm 11.4)$ & 0.04 \\
\hline Readmissions at 3 months & $42(32.8 \%)$ & $13(56.5 \%)$ & 0.03 \\
\hline
\end{tabular}

\section{Discussion}

This clinical trial showed that our program was able to reduce readmissions for $\mathrm{HF}$ patients with reduced ejection fraction at 6 months. Our program emphasized on education, optimization of HF medications and early follow-up visits at 7 days and 1 month after discharge from the index hospitalization. During this period patients were following a special diet with fluids and salt restrictions and were monitored for any increase in body weight for more than $3-5 \mathrm{~kg}$. They were educated not to exceed the targets level for fluids (1.5 liters per day) and salt (2gm per day). They were exercising for at least 30 minutes per day for 5 days per week. In addition to titration of their HF medication to reach the target doses recommended by international guidelines. We stressed on the early followup visit as it was the most critical intervention in our trial. It was shown previously that patient behavioral factors such as non-adherence to diet and medications, economic and social factors frequently contribute to re-hospitalizations [20-22]. The traditional model of care delivery is thought to contribute to frequent hospitalizations because of brief episodic encounters, little attention to the common modifiable factors that precipitate many hospitalizations. All disease management programs with different interventions were done worldwide aiming to decrease readmissions. However, some where successful and other were not. This trial was examining the effectiveness of such a program in comparison to regular care in the Lebanese population.

The crucial part of our program is the early follow-up visits. Our population is somehow different from other populations. In most countries, patients receive the majority of medical care for free or little amount of money to be paid from their pockets. However, in Lebanon the medical care is not for free. Thus, the majority of patients have to pay for their medications and physicians' follow-up form their pockets. This will greatly impact the usual follow-up on these patients. The disease management program allowed patients to be seen and closely monitored by a nurse. The early recognition of decompensation and the early education on self-care have made the major impact on their outcome.

A randomized trial of an education and support intervention to prevent readmissions of patients with HF was published in Journal of the American College of Cardiology in 2002 [23]. Our study is similar to their study on the components of the education but unlike their study, we emphasize not only education but also optimization of care and augmentation of HF medications on the follow-up visits that were at different periods and duration than their study. They recruited 88 patients (44 intervention and 44 control) in their study. Their intervention was associated with a $39 \%$ decrease in the total number of readmissions (intervention group: 49 readmissions; control group: 80 readmissions, $\mathrm{P}-0.06$ ). After adjusting for clinical and demographic characteristics, the intervention group had a significantly lower risk of readmission compared with the control group (P-0.03). However in our study the readmissions at 6 months was significantly lower in the intervention arm (28.2\% DMP group vs. 57.5\% control group) $(\mathrm{P}<0.001)$. Thus education plus modification of medical regimen were more effective in reducing readmissions than education alone.

Another randomized trial in Canada assigned 230 eligible patients who had experienced an acute episode of congestive HF to standard care $(n=115)$ or follow-up at a multidisciplinary specialized HF outpatient clinic $(n=115)$ [24]. The study team evaluated patients in the intervention group within 2 weeks of hospital discharge. A monthly follow-up plan was developed which is different from our follow up visits plan. At the first clinic visit patient education was similar to our study as well as the education reinforcement at each subsequent clinic visit. The primary outcomes were all-cause hospital admission rates and total number of days in hospital at 6 months. At 6 months, fewer patients in the intervention group had required readmission to hospital than patients in the control group (39\%) vs. (57\%). This is similar to our results we had $28.2 \%$ of the patients readmitted at 6 months in the DMP group vs. $57.5 \%$ in the control group $(\mathrm{P}<0.001)$. Thus early follow-up after 1 week, 1 month and then every 3 months for a total 6 months period was as effective as more frequent follow-up visits within 2 weeks and then every month for a total of 6 months in reducing readmission rates for heart failure in comparison with the regular care. 
The DMP as compared with the usual care for HF patients with reduced ejection fraction reduced the number of hospital readmissions at 6 months and mortality. Thus, this program can help to generate policies and recommendations for establishing heart failure clinics and DMP in Lebanon.

\section{Limitations}

The main limitation of this study is the sample size and nonrandomization. However, both groups were identical at baseline without major confounding factors. We were able to show a significant difference in the readmission rates between the two groups. Moreover, it is a single center trial. It is unclear what will be the effect of such a program in different centers in Lebanon. However, RHUH is the largest University Hospital in Lebanon that admits all categories of patients from both the public and private sectors. Thus the sample of patients with heart failure in this study may represent the majority of heart failure patients in Lebanon.

\section{Conclusion}

Our HF-DMP that entailed close follow-up after discharge with education, diet, exercise and augmentation of $\mathrm{HF}$ medications decreased all cause readmission rates at 6 months for patients with HF and reduced ejection fraction. Moreover, this program tends to lower mortality when compared to regular care in the Lebanese population.

\section{Acknowledgement}

We thank our research coordinators, pharmacy, nurses, medical students and secretaries for their help.

\section{Funding}

This study was supported by grants from clinical research unit at Rafik Hariri University Hospital (grant number not applicable).

\section{References}

1. Najafi F, Jamrozik K, Dobson AJ (2009) Understanding the epidemic of heart failure: a systematic review of trends in determinants of heart failure. Eur J Heart Fail 11(5): 472-479.

2. Hunt SA, Abraham WT, Chin MH, Feldman AM, Francis GS, et al. (2009) 2009 focused update incorporated into the ACC/AHA 2005 guidelines for the diagnosis and management of heart failure in the adults: a report of the American College of Cardiology Foundation/American Heart Association Task Force on Practice Guidelines Developed in Collaboration With the International Society for Heart and Lung Transplantation. J Am Coll Cardiol 53(15): e1-e90.

3. Dickstein K, Cohen-Solal A, Filippatos G, McMurray JJ, Ponikowski P, et al. (2008) ESC Committee for Practice Guidelines (CPG). ESC Guidelines for the diagnosis and treatment of acute and chronic heart failure 2008. The Task Force for the Diagnosis and Treatment of Acute and Chronic Heart Failure 2008 of the European Society of Cardiology. Developed in collaboration with the Heart Failure Association of the ESC (HFA) and endorsed by the European Society of Intensive Care Medicine (ESICM). Eur J Heart Fail 10(10): 933-989.

4. Lloyd-Jones D, Dams RJ, Brown TM, Carnethon M, Dai S, et al. (2010) American Heart Association Statistics Committee and Stroke Statistics Subcommittee. Heart disease and stroke statistics-2010 update: a report from the American Heart Association. Circulation 121(7): e46-e215.

5. LiuL (2011) Changes in cardiovascular hospitalization and comorbidity of heart failure in the United States: findings from the National Hospital Discharge Surveys 1980-2006. Int J cardiol 149(1): 39-45.

6. Jencks SF, Williams MV, Coleman EA (2009) Rehospitalizations among patients in the Medicare fee-for-service program. N Engl J Med 360(14): 1418-1428.

7. Yancy CW, Jessup M, Bozkurt B, Butler J, Casey DE, et al. (2013) 2013 ACCF/AHA guideline for the management of heart failure. A report of the American College of Cardiology Foundation/American Heart Association. Task force on practice guidelines. J Am Coll Cardiol 62(16): e147-e239.

8. Bueno H, Ross JS, Wang Y, Chen J, Vidán MT, et al. (2010) Trends in length of stay and short-term outcomes among Medicare patients hospitalized for heart failure, 1993-2006. JAMA 303(21): 2141-2147.

9. Steiner C, Barrett M, Weiss A (2012) Healthcare and Utilization project (HCUP) projections.

Cardiovascular/Cerebrovascular Conditions and Procedures 2001 to 2012. HCUP Projections Report \# 2012-02. USA Agency for healthcare research and quality, USA.

10. Gheorghiade M, Zannad F, Sopko G, Klein L, Piña IL, et al. (2005) Acute heart failure syndromes: current state and framework for future research. Circulation 112(25): 3958-3968.

11. Nieminen MS, Brutsaert D, Dickstein K, Drexler H, Follath F, et al. (2006) Euro Heart Failure Survey II (EHFS II): a survey on hospitalized acute heart failure patients: description of population. Eur Heart J 27: 2725-2736.

12. Cleland JG, Swedberg K, Follath F, Komajda M, Cohen-Solal A, et al. (2003) The EuroHeart Failure survey programme-a survey on the quality of care among patients with heart failure in Europe. Part 1: patient characteristics and diagnosis. Eur Heart J 24: 442-463.

13. Maggioni AP, Dahlstrom U, Filippatos G, Chioncel O, Crespo Leiro M, et al. (2013) On behalf of the Heart Failure Association of the European Society of C. EURObservational Research Programme: regional differences and 1-year follow-up results of the Heart Failure Pilot Survey (ESC-HF Pilot). Eur J Heart Fail 15(7): 808-817.

14. Adams KF, Lindenfeld J, Arnold JMO, Baker DW, Barnard DH, et al. (2006) Heart Failure Society of America: HFSA 2006 Comprehensive Heart Failure Practice Guideline. J Card Fail 12(1): e1-e122.

15. Fonarow GC, Stevenson LW, Walden JA, Livingston NA, Steimle AE, et al. (1997) Impact of a comprehensive heart failure management program on hospital readmission and functional status of patients with advanced heart failure. J Am Coll Cardiol 30(3): 725-732.

16. Hanumanthu S, Butler J, Chomsky D, Davis S, Wilson JR (1997) Effect of a heart failure program on hospitalization frequency and exercise tolerance. Circulation 96(9): 2842-2428.

17. West JA, Miller NH, Parker KM, Senneca D, Ghandour G, et al. (1997) A comprehensive management system for heart failure improves clinical outcomes and reduces medical resource utilization. Am J Cardiol 79(1): 58-63.

18. Savard LA, Thompson DR, Clark AM (2011) A meta-review of evidence on heart failure disease management programs: the challenges of describing and synthesizing evidence on complex interventions. Trials 12: 194 .

19. Iraurgui BA, Muniz J, Rodriguez-Fernandez JA, Vidán-Martínez L, Silva-César M, et al. (2007) Randomized controlled clinical trial of a home care unit intervention to reduce readmission and death rates in patients discharged from hospital following admission for heart failure. Rev Esp Cardiol 60(9): 914-922. 
20. Hunt SA, Baker DW, Chin MH, Cinquegrani MP, Feldman AM, et al. (2001) ACC/AHA guidelines for the evaluation and management of chronic heart failure in the adult: executive summary. A report of the American College of Cardiology/American Heart Association Task Force on Practice Guidelines (Committee to revise the 1995 Guidelines for the Evaluation and Management of Heart Failure). J Am Coll Cardiol 38(7): 2101-2113.

21. Havranek EP, Wolfe P, Masoudi FA, Rathore SS, Krumholz HM, et al. (2004) Provider and hospital characteristics associated with geographic variation in the evaluation and management of elderly patients with heart failure. Arch Intern Med 164(11): 1186-1191.

This work is licensed under Creative Commons Attribution 4.0 License
22. Moser DK, Mann DL (2002) Improving outcomes in heart failure: it's not unusual beyond usual care. Circulation 105(24): 2810-2812.

23. Krumholz HM, Amatruda J, Smith GL, Mattera JA, Roumanis SA, et al. (2002) Randomized trial of an education and support intervention to prevent readmission of patients with heart failure. J Am Coll Cardiol 39(1): 83-89.

24. Ducharme A, Doyon O, White M, Rouleau JL, Brophy JM (2005) Impact of care of a multidisciplinary congestive heart failure clinic: a randomized trial. CMAJ 173(1): 40-45.

\section{Your next submission with Juniper Publishers will reach you the below assets}

- Quality Editorial service

- Swift Peer Review

- Reprints availability

- E-prints Service

- Manuscript Podcast for convenient understanding

- Global attainment for your research

- Manuscript accessibility in different formats

( Pdf, E-pub, Full Text, Audio)

- Unceasing customer service

Track the below URL for one-step submission

https://juniperpublishers.com/online-submission.php 